\title{
Renal Pelvis Fistula
}

National Cancer Institute

\section{Source}

National Cancer Institute. Renal Pelvis Fistula. NCI Thesaurus. Code C78595.

An abnormal communication between the renal pelvis and another anatomic site. 